\title{
Bistatic Scattering due to Hydrometeors on Cochannel Intersystem Communication Links over a Subtropical Path
}

\author{
P. A. Owolawi and T. Wallingo \\ Department of Electrical, Electronics and Computer Engineering, University of KwaZulu-Natal, Private Bag X54001, \\ Durban 4000, South Africa
}

Correspondence should be addressed to P. A. Owolawi; owolawi@mut.ac.za

Received 2 May 2014; Revised 27 August 2014; Accepted 28 August 2014; Published 30 October 2014

Academic Editor: Tat Soon Yeo

Copyright ( 2014 P. A. Owolawi and T. Wallingo. This is an open access article distributed under the Creative Commons Attribution License, which permits unrestricted use, distribution, and reproduction in any medium, provided the original work is properly cited.

\begin{abstract}
The performance of fixed satellite systems in the shared frequency band depends on the tolerance level of interference between them. Interference disturbs the functionality of the ground station and causes signal degradation. The knowledge of interference level must therefore be known for an optimal satellite design. In this work, we evaluate interference due to hydrometeors for a situation in which a satellite downlink signal is affected by the signal from a terrestrial microwave network operating at the same frequency as the satellite system in a subtropical station: Durban, South Africa. The evaluation of the transmission loss is based on the modified 3$\mathrm{D}$ bistatic radar equation and the exponential rain cell model for the scattering. The results of intersystem interference for different station separation over frequencies variation, terrestrial antenna gains, and exceedance probabilities are presented. The effect of the additional rain attenuation $\left(A_{w}\right)$ on the satellite signals is also examined. The results point out to some remarkable attenuation differences between the effective transmission loss and the transmission loss statistics for small time unavailability at the frequencies considered in this work. This could be detrimental in link budget design if overlooked.
\end{abstract}

\section{Introduction}

Intersystem interference is caused by an undesired signal received from a transmitter of a different system. The cochannel interference arises due to the other carriers transmitted by the satellite to earth stations of the same system, at the same frequency, and at the same polarisation as the useful carrier. These interfering carriers are usually sent to earth stations located in a different spot beam as the useful earth station frequency-division multiple access (FDMA) and timedivision multiple access (TDMA) but located in the same spot beam as the useful earth station in code-division multiple access (CDMA) [1]. Transmissions of the interfering carriers (microwave systems) between two highly directional antennas are usually done through the electromagnetic waves.

The media traversed by the electromagnetic waves and the spectrum used are shared. The need for the frequency sharing has been due to the congestion experienced at the lower frequency bands. This has resulted into the move to higher frequency to gain more bandwidth. However, at higher frequencies and most especially at frequencies above $10 \mathrm{GHz}$, the most serious problems in system design emanate from attenuation, depolarization, and scattering interference by precipitation particles along the radio path [2]. The weak signal from the satellite is liable to severe interference from a strong terrestrial system operating in its neighbourhood at the same frequency if their beam canters intersect and contain precipitating particles [3]. Interference hampers coverage and capacity and limits the effectiveness of both new and existing communication systems. In addition to the aforementioned fact, a proper link budget calculation requires the knowledge of interference through the desired carrier to interfering signal level (C/I) - the ratio of the useful carrier power to the interfering carrier power. Therefore, assessing the extent of such interference on statistical terms is very important for the correct design of communication systems operating at microwave and millimetre wave frequency for optimum performances.

The study on the impact of interference based on the evaluation of bistatic interference on communication paths 
has drawn much attention at the temperate and the tropical region. The report of some researchers at the temperate region includes the works of Crane [4], Awaka [5], Capsoni et al., [2], Olsen et al., [6], Holt et al., [7], Capsoni and D'Amico [8], and Sitorus and Glover [9] to mention but few, while at the tropical region and mostly in Nigeria are the works of Ajewole et al., [10, 11], Ajewole and Ojo [3], Ojo et al., [12], and Ojo and Joseph-Ojo [13] among others. In the previous works, the subtropical climate has always been categorized under the tropical region. However, the results obtained in such studies cannot be applied directly on the subtropical paths. The reason is due to differences in subtropical and tropical climates. A tropical climate has high temperature and high humidity, while a subtropical climate has high temperature and low humidity. Rainfall is more of stratiform type, with lesser intensity in the subtropical region when compared to the tropical region where rainfall is more of convective type. The peculiarity of these characteristics called for the investigation of the degree of interference due to hydrometeors that could be encountered in a situation in which a satellite downlink signal is affected by the signal from a terrestrial microwave network operating at the same frequency as the satellite system in the subtropical region. This has rarely been done for a subtropical link.

In this work, we evaluated the intersystem interference, $(L)$, and the effective transmission loss, (Le), on the transmission of horizontally polarized signals in the subtropical climate when a satellite downlink path is crossed by the path of a terrestrial microwave link network operating at the same frequency. Often, an estimate of intersystem interference due to hydrometeor scattering is usually carried out on the vertically polarized microwave signals into the receiver on earthspace communications systems operating at the same frequency; the horizontal polarization is usually not investigated because coupling between the transmitting and receiving systems is much less than in vertical polarization $[1,4-7]$. However, as this is true in the temperate regions, the nature and characteristics of tropical and subtropical rainfall, which are quite distinct from the temperate rainfall, mean that the horizontal polarization when transmitted should be investigated for hydrometeor induced interference in this region. We have adopted the modified version of the Capsoni and D'Amico [8] 3D exponential model based on thunderstorm rain types which predominates the subtropical region. Figure 1 presents the scattering geometry between the terrestrial station and an earth satellite station as well as the additional rain attenuation, $A_{w}$, on the path of satellite signal, which can further reduce the signal-to-noise ratio of the satellite terminal.

\section{Rain Scatter Techniques}

2.1. Scatter Model. The transmission loss based on the Bistatic Radar Equation (BRE) can be expressed as $[4,5]$

$$
\frac{1}{L}=\frac{P_{r}}{P_{t}}=\iiint_{V c} \frac{\lambda^{2} G_{1} G_{2} A_{1} A_{2}}{(4 \pi)^{3} R_{1}^{2} R_{2}^{2}} \sigma_{b i} \exp \left(-r_{1}-r_{2}\right) d V,
$$

where $\lambda$ is the wavelength in meters, $P_{r}\left(P_{t}\right)$ is the received (transmitter) power, $G_{1}$ is the transmitter antenna gain, $G_{2}$ is the receiver antenna gain, $A_{1}$ is the attenuation at the path from the transmitter to the common volume, $A_{2}$ is the attenuation at the path from the common volume to the receiver, $R_{1}\left(R_{2}\right)$ is the distance of the transmitter (ground station receiver) from the common volume, $\sigma_{b i}$ is the scatter cross section of each point in the common volume, and $r_{1}$ and $r_{2}$ the optical distances from the transmitter to $d V$ and from $d V$ to the receiver, respectively.

The equation assumed the scattering process through the single scattering narrow-beam width antenna. The scatter cross-section per unit volume is estimated using the complete Mie solution or Rayleigh approximation. Hence, using the narrow-beam approximation equation (1) takes the form

$$
\frac{1}{L}=\frac{P_{r}}{P_{t}}=\frac{A_{1} A_{2} G_{1} G_{2} \lambda_{2} A_{g} \sigma_{b i}}{(4 \pi)^{3}} \mathrm{Cv}
$$

where $A_{g}$ is the extra attenuation due to gaseous absorption and $\sigma_{b i}$ is the scattering cross-section. The parameter $\mathrm{Cv}$ is the common volume which denotes the region formed by the intersection of the cones of the radiation patterns of the two antennas cut at the $-18 \mathrm{~dB}$ level which is evaluated from the following integral [8]:

$$
\mathrm{Cv}=\int_{0}^{\infty} \frac{F_{1}\left(\vartheta_{1}, V_{1}\right) F_{2}\left(\vartheta_{2}, V_{2}\right)}{R_{1}^{2} R_{2}^{2}} d V .
$$

The quantities $F_{1}\left(\vartheta_{1}, V_{1}\right)$ and $F_{2}\left(\vartheta_{2}, V_{2}\right)$ represent the directivity function of the transmitting and receiving antenna systems and are calculated in terms of their effective area. $\mathrm{Cv}$ only needs to be evaluated numerically once for a given geometry (assuming Gaussian directivity functions) and, consequently, a single interference level only requires two dimensional integrals to be calculated [2].

At frequencies less than $10 \mathrm{GHz}$, the scattering crosssection per unit volume of precipitation, $\sigma_{b i}$, at the top of melting layer can be expressed using the Rayleigh approximation as

$$
\sigma_{b i}=\left(10^{-18}\right) \frac{\pi^{5}}{\lambda^{4}}\left|\frac{\varepsilon-1}{\varepsilon+2}\right|^{2} Z\left(\mathrm{~m}^{2} / \mathrm{m}^{3}\right)
$$

where $\lambda$ is the wavelength in meters, $\varepsilon$ is the complex relative permittivity of the medium, that is frequency, convenient drop temperature, and particle phase dependent, the radar reflectivity, $Z\left(\mathrm{~mm}^{6} \mathrm{~m}^{-3}\right)$ is the sum of the sixth powers of the diameters of all hydrometeors per unit volume and is related to the point rain rate $R$ as

$$
Z=10 \log \left(a R^{b}\right)
$$

where $R$ is the rainfall rate $(\mathrm{mm} / \mathrm{h})$. The parameters " $a$ " and " $b$ " for the thunderstorm rainfall type are based on the lognormal rain drop size distribution (DSD) as discussed in [14]. It must be noted that for the frequencies greater than $10 \mathrm{GHz}$ the Mie solution method is fully adopted.

The extra attenuation that the signal experiences along the path towards and from the common volume is also taken into consideration for interference prediction in this work. According to [8], the two factors that contributed to 


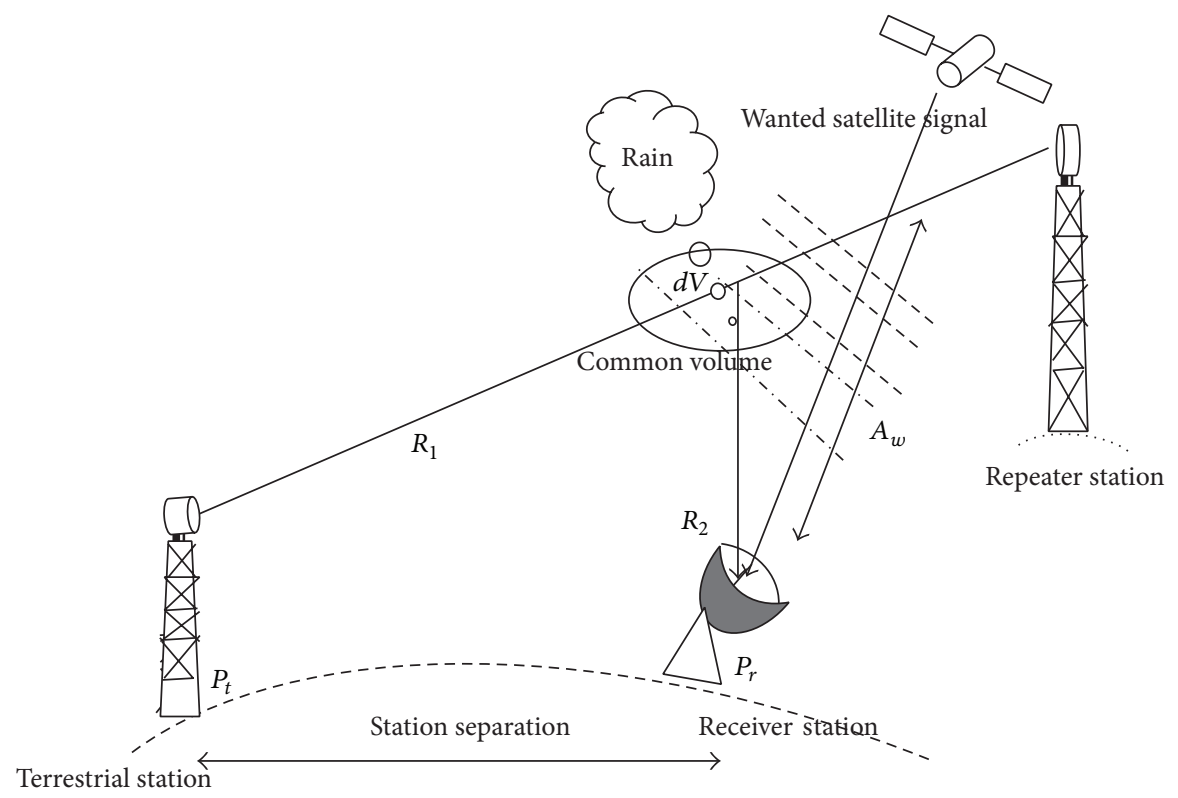

FIGURE 1: The rain scattering geometry with additional rain attenuation, $A_{w}[3]$.

attenuation come from precipitation and, to a lesser extent, the atmospheric gases. The attenuation due to atmospheric gases was calculated using the ITU-R Rec. 676-5 [15], while attenuation of the signals due to rain along a radio path was evaluated using the power law relationship between attenuation and rain rate as

$$
A=k R^{\alpha}
$$

where the constant parameters $k$ and $\alpha$ for calculating attenuation $A$ for thunderstorm rain valid for the subtropical region used in this study are shown in Table 1 for horizontally polarized signals only and for the frequencies investigated $[16,17]$.

The knowledge of both vertical and horizontal spatial distributions of rain rate is also important in the estimation of interference level. A rain cell has been defined as any connected region of space composed of points where the rainfall rate exceeded a given intensity threshold [18]. As earlier stated, the vertical structure of rain can be taken care of by assuming the rain rate to be constant with height up to the $0^{\circ} \mathrm{C}$ isotherm height. Above this height is the ice region where the reflectivity factor $Z$ is also assumed to decrease by a constant factor of $6.5 \mathrm{~dB} / \mathrm{km}$ [18]. For the horizontal structure of rain, we have adopted the procedure used by [8] based on the exponential rain cell model. Within the horizontal cell, rain rate distribution is assumed to vary exponentially with rotational symmetry at points $x$ and $y$ and can be analytically expressed as

$$
R(x, y)=R_{m} e_{o}^{-r / r},
$$

where $r$ is the radial distance with coordinate $(x, y)$ from the rain cell centre, $R_{m}$ is the maximum rainfall rate, and $r_{o}$ is the parameter characterizing the cell size. Equation (7) represents the statistical behavior of the rainfall rate profiles along a path
TABLE 1: Power law attenuation parameters for thunderstorm rain type [16].

\begin{tabular}{lcc}
\hline Frequency $(\mathrm{GHz})$ & $k$ & $\alpha$ \\
\hline 4 & 0.0003 & 1.0325 \\
6 & 0.0032 & 1.0056 \\
7 & 0.0046 & 1.0980 \\
8 & 0.0043 & 1.3562 \\
10 & 0.0175 & 1.1443 \\
12 & 0.0285 & 1.1211 \\
15 & 0.0476 & 1.0698 \\
20 & 0.0998 & 1.0421 \\
25 & 0.1356 & 1.0312 \\
30 & 0.1161 & 1.0426 \\
35 & 0.2002 & 0.9910 \\
40 & 0.3234 & 0.9971 \\
45 & 0.3967 & 0.9423 \\
50 & 0.5284 & 0.8379 \\
60 & 0.5830 & 0.8307 \\
\hline
\end{tabular}

and is found to be able to reproduce the point rainfall rate cumulative distribution $P(R)$ well enough $[2,3]$.

This study assumes the proposed form of the simplified Capsoni 3D model for the characteristic distance $r_{o}(\mathrm{~km})$ over which the rain rate decreases to $e^{-1}$ value as

$$
r_{o}\left(R_{m}\right)=1.7\left[\left(\frac{R_{m}}{6}\right)^{-10}+\left(\frac{R_{m}}{6}\right)^{-0.26}\right] \mathrm{km} .
$$

In order to give room for the differences in the rain cell from one location to another, the probability of occurrence of each cell in practice is represented by the cell spatial density. The probability of occurrence of rain cell is defined in terms of the total number of rain cells $N^{*}\left(R_{m}\right)$ for a given area per 
unit rain rate $R(r)$. A general retrieval algorithm for $N^{*}$ as proposed by Capsoni et al. [2] can be expressed as

$$
N^{*}\left(R_{m}\right)=N_{0}^{*}\left(R_{m}\right) \exp \left(\frac{-r_{o}}{\overline{r_{o}}\left(R_{m}\right)}\right),
$$

where $N_{0}^{*}$ is the spatial density of cells with peak $R_{m}$ regardless of the value of $r_{o}$. A log-power-law expression of (9) was then adopted to define the measured values of $P(R)$ for $0<$ $R<R^{\prime}$. This is expressed as [8]

$$
P(R)=P_{o} \ln \left(\frac{R^{\prime}}{R}\right)^{k} .
$$

$P_{o}$ and $k$ can be obtained by interpolation using the least square techniques from the cumulative distribution of the measured point rain rate $P(R) . R^{\prime}$ is normally assumed to be about four times the highest rain rate at the location of interest $[3,5]$. The summary of $P_{o}, R^{\prime}$, and $k$ obtained for Durban as well as the path geometries used for calculating transmission loss is shown in Table 2.

As already stated, an extra attenuation could also be observed along the wanted path from additional attenuation due to rain; this extra attenuation reduces the signal-to-noise $(\mathrm{S} / \mathrm{N})$ ratio at the receiver's end. The effective transmission loss Le is defined as the difference between the transmission loss $L$ and the extra attenuation $A_{w}$ along the wanted path as depicted in Figure 1. Hence, Le can be expressed as

$$
\mathrm{Le}=L-A_{w}=P_{t}-\left(P_{r}+A_{w}\right)(\mathrm{dB}),
$$

where $A_{w}$ is the extra attenuation on the path of satellite signal, which further reduces the signal-to-noise ratio of the satellite terminal.

2.2. Methodology. In this study, we used the subtropical lognormal raindrop size distribution proposed by [17] as applicable to the subtropical stations, and, for the distribution fit for the convective thunderstorm rain type, we have used the Z-R relationship proposed by Ajayi and Owolabi [14] for thunderstorm rain which is based on a log-normal fit. This study covers the frequency range $4-40 \mathrm{GHz}$ (C-Q/V band) used presently by most service providers for terrestrial and earth-space communications. The mean annual cumulative distribution of point rain rate $P(R)$ measured at Durban [19] is used to predict interference levels with the probability of occurrence ranging from $1 \%$ to $10^{-3} \%$. The attenuation of the signals due to rain was evaluated using the power law relationship between attenuation and rain rate, while an average water vapour density of $20 \mathrm{~g} / \mathrm{m}^{3}$ was assumed to calculate attenuation due to atmospheric gases using the ITU-R Rec. 836-5 [20]. Water temperature of $20^{\circ} \mathrm{C}$ was also assumed to calculate the refractive index of water using the method of Ray [21]. The $0^{\circ} \mathrm{C}$ isotherm heights during rainy conditions $h_{\mathrm{FR}}$ vary from 3.80 to $4.25 \mathrm{~km}$ in South Africa.

2.2.1. Interference from Intelsat IS-17 to Terrestrial Links over Foot Print of Durban. The interference is produced at the input of the received earth station, by carriers transmitted

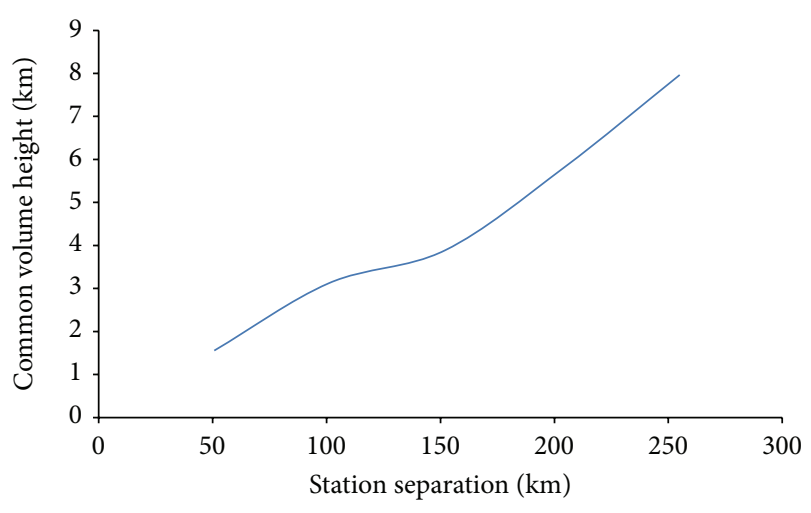

FIGURE 2: Equivalent satellite to common volume distance and the corresponding station separation.

by either the satellite of the considered system or a satellite of another system. In an ideal system, these carriers should be strongly attenuated, due to multiplex scheme, frequency and polarization plan, antenna pattern, and filtering issues. Several of these parameters are considered in this study as a result of interference caused by rain and melting-snow. The input parameters needed consist of the geometric and electrical properties of the link, as well as the meteorological parameters. For the purpose of this work, we have used the Intelsat 17 (IS-17) a geostationary satellite located at $66^{\circ} \mathrm{E}$ with its service footprint over Durban, South Africa. A GEO satellite has been known to offer a 24-hour view of a particular area, which leads to its wide use as a provider for broadcast satellite services (BSS) and multipoint applications. These parameters are summarized in Table 3.

\section{Results and Discussion}

In this section, we will discuss the results of the transmission loss and the effective transmission loss simulated based on the SBRE [2] and the exponential rain cell model of [8] for downlink transmission on a propagation path in Durban South Africa. The simulation is based on distance separation between the transmitting and receiving station, frequency dependent, variation of terrestrial antenna gain, and percentage unavailability of the wanted signal.

Figure 2 presents the equivalent satellite to common volume distance and the corresponding station separation. The common volume is calculated once and for all, for geometry irrespective of the other input parameters, and the extent of the rain cells by integrating (4) using a three dimensional Simpson integration algorithm. The result shows that the common volume $(\mathrm{Cv})$ increases linearly as station separation increase. At station separation longer than about $150 \mathrm{~km}$, the common volume will be in the ice region, where ice scattering is dominant. In this case, the $\mathrm{Cv}$ will be above rain height and be subjected to a considerable higher interference as compared to when it is below the rain height. This is contrary to the scenario observed in the tropical region, where the $\mathrm{Cv}$ is at the ice region at station separation longer than about $170 \mathrm{~km}[23]$. 
TABLE 2: Power law parameters for the cumulative probability density for thunderstorm convective rain type and the path geometries for calculating transmission loss.

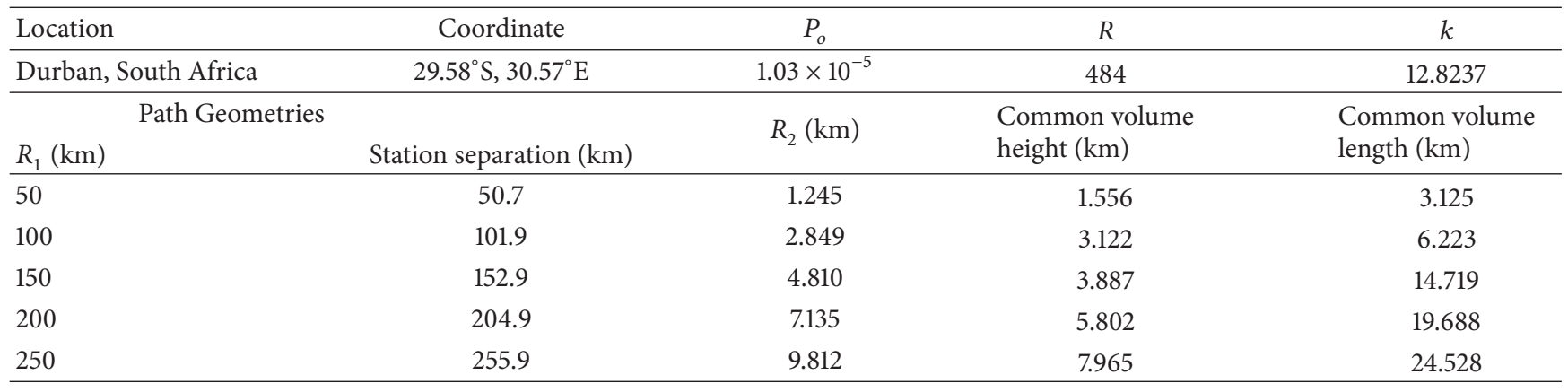

TABLE 3: The input parameters needed: the geometric and electrical properties of the link and meteorological parameters [22].

\begin{tabular}{lc}
\hline Station Name & Durban, South Africa \\
Location & $29.58^{\circ} \mathrm{S}, 30.57^{\circ} \mathrm{E}$ \\
Frequency range & $4-40 \mathrm{GHz}$ \\
Elevation above sea level & $0.008 \mathrm{~km}$ \\
Rain type considered & Thunderstorm \\
$0^{\circ}$ C isotherm & $3.8-4.25 \mathrm{~km}$ \\
Transmitting antenna & $1^{\circ}$ \\
Elevation angle & 26.3 \\
Gain & Horizontal \\
Beam width & \\
Polarization & $38.5^{\circ}$ \\
Receiving antenna & 37.14 \\
Elevation angle & $0.15^{\circ}$, Gaussian radiation pattern \\
Gain & Horizontal \\
Beam width & $461 R^{1.31}$ \\
Polarization &
\end{tabular}

The variation of the total gaseous attenuation (sum of gaseous attenuation in the 1st and 2nd links) over the station separation is presented in Figure 3. The variation was observed at various frequencies that span over to Q-band. It could be observed that there is gradual increase of gaseous attenuation from path length window $100-150 \mathrm{~km}$ and got to the peak at exactly longer path lengths of $150 \mathrm{~km}$ before attaining a saturation state at longer path lengths greater than $150 \mathrm{~km}$. The implication is that, at station separation greater than $150 \mathrm{~km}$, there is a strong decrease in radar reflectivity since the $\mathrm{Cv}$ at this distance is in the ice region, $3.89 \mathrm{~km}$. Thus, the ice scattering predominates over rain scattering for a common volume located in the ice region. We also observed a consistent increase in total attenuation along the station separation up to frequency of $16 \mathrm{GHz}$. However, at frequency greater than $16 \mathrm{GHz}$, this observation does not hold as different frequency shows different variation of gaseous attenuation over the station separation.

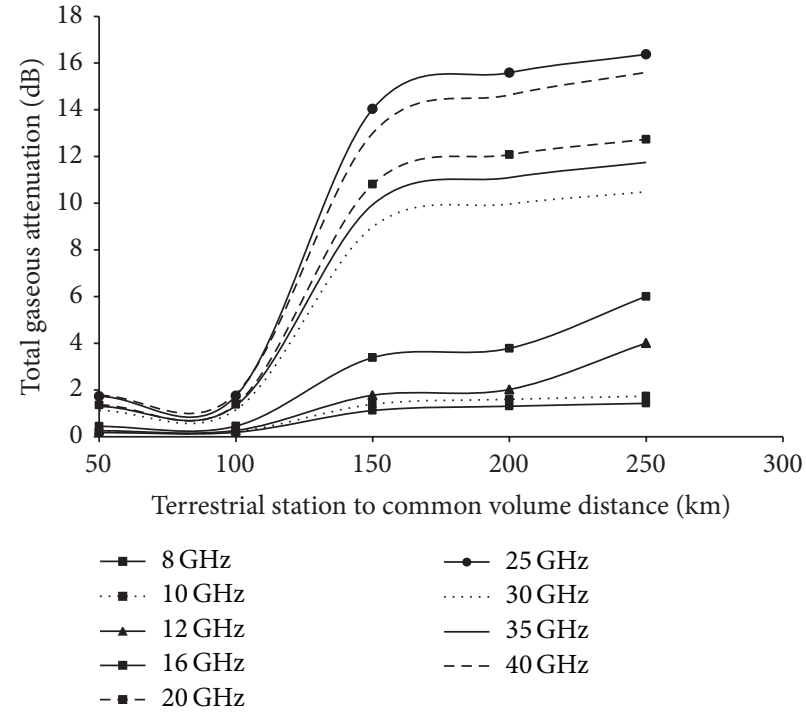

FIGURE 3: Variation of the total gaseous attenuation (sum of gaseous attenuation in the 1st and 2 nd link) over the station separation at different frequencies.

In Figures 4(a) and 4(b), we compare $L$ with terrestrial to common volume distance at two frequencies 12 and $30 \mathrm{GHz}$, respectively, for varying time percentage unavailability in the study location. Generally, $L$ increase with increase in increased with increasing terrestrial (TS) to common volume (Cv) distance (or terrestrial to satellite antenna separations, T-R). The sudden decrease could also be observed at longer path lengths window $100-150 \mathrm{~km}$ due to the decrease effect in radar reflectivity. This is more pronounced at a $\mathrm{Ku}$ band frequency (Figure 4(a)) when compared with the Ka band frequency (Figure 4(b)). Also, at TS-Cv distance of $50 \mathrm{~km}$ (T-R of $50.7 \mathrm{~km}$ ) and time probability of $0.01 \%, L$ is about 129 and $132 \mathrm{~dB}$, respectively, at 12 and $30 \mathrm{GHz}$. At the time percentage of 0.001 , the values are down to about 124 and $129 \mathrm{~dB}$ for these frequencies.

It is obvious from the results that as the distance from the TS-Cv increases, $L$ increases. This means that the closer the station, the higher the interference received in the satellite channel since the interfering signal arrives weaker due to its increased path attenuation. 


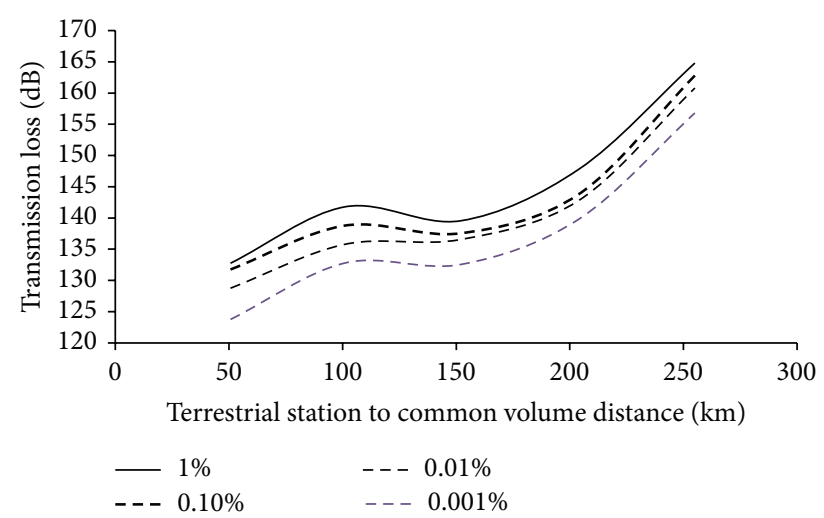

(a)

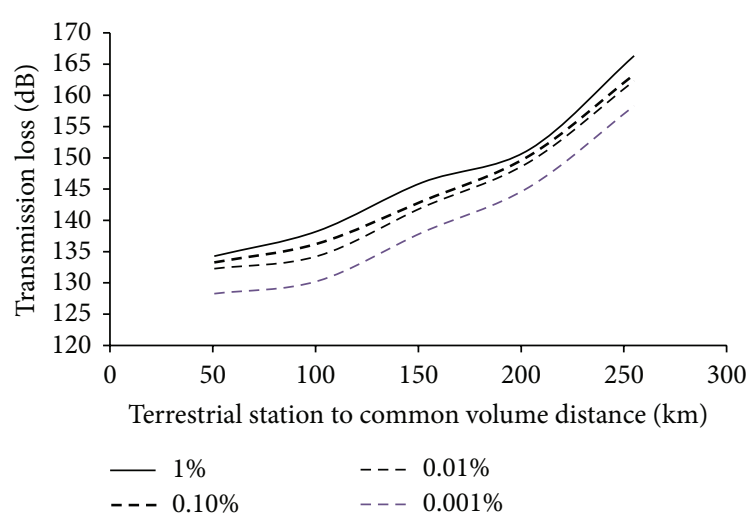

(b)

FIGURE 4: Variation of the transmission loss with the terrestrial station antenna to common volume distance at some percentage of time and at frequency of (a) $12 \mathrm{GHz}$ and (b) $30 \mathrm{GHz}$.

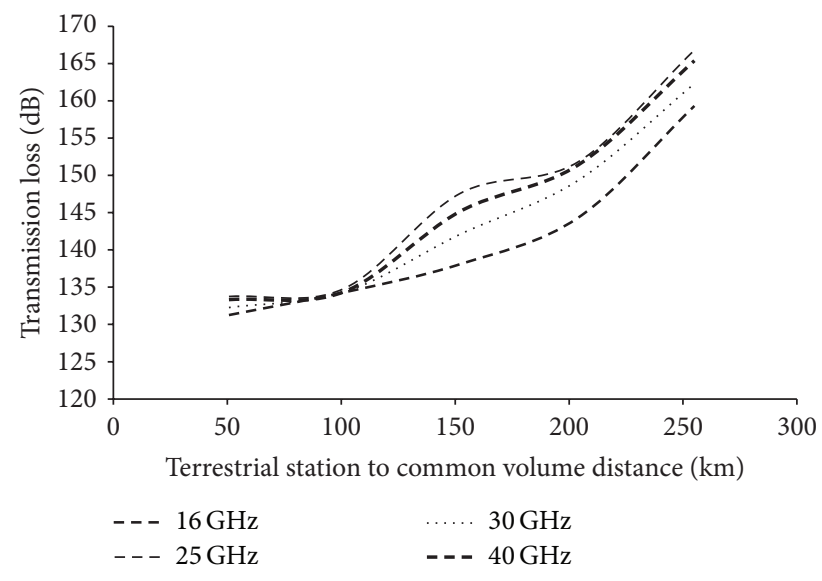

FIGURE 5: Influence of the terrestrial propagation path length on the transmission loss at different frequencies and time availability of $99.9 \%$.

We also examine the influence of the terrestrial propagation path length on the transmission loss at frequencies 16, 25, 30 , and $40 \mathrm{GHz}$ and time availability of $99.9 \%$ as presented in Figure 5. We observed that transmission loss increases gradually with increasing antenna separation (less interference) over each of the frequency. Also, the transmission loss at higher frequencies $(25$ and $40 \mathrm{GHz}$ ) is significantly higher than at other frequencies due to the larger path attenuation of the signal. However, at lower frequency and at distance $R_{1}$ greater than $150 \mathrm{~km}$, the contribution from ice begins to dominate because of the blocking effect of the earth.

Figure 6 presents a better view of the influence of the transmission loss with frequency at some percentage exceedance over long and short propagation path lengths. At both path lengths, the graph shows a sinusoidal trend. At short path length, there is an increase in the value of $L$ at very low frequency less than $10 \mathrm{GHz}$. However, at frequency greater than $10 \mathrm{GHz}, L$ decreases (increase in interference) with increasing frequency except at the frequency window of 12$20 \mathrm{GHz}$ where there is slight increase due to radar reflectivity

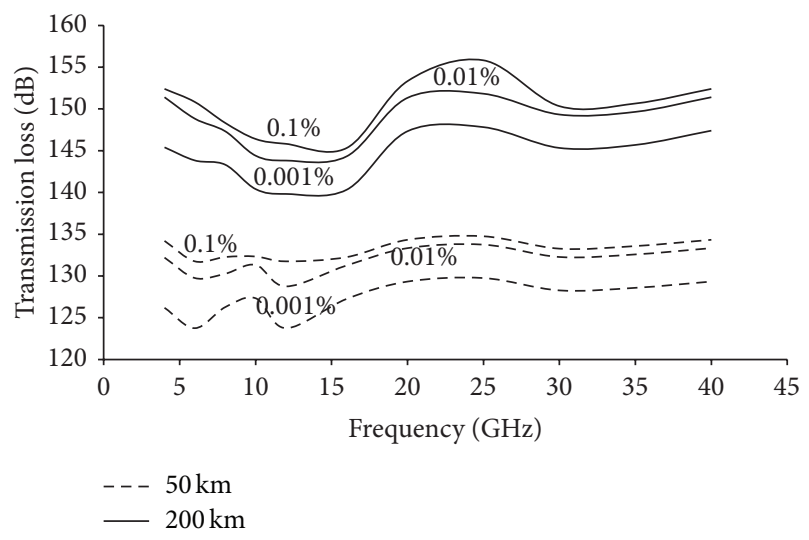

FIgURE 6: Variation of the transmission loss with frequency at some percentage exceedance and for long and short propagation path lengths.

factor. The decrease in $L$ with increasing frequency at the short path length may be due to contribution of the rain atmospheric gases attenuation effect of the wanted signal. Also at lower frequencies and long path lengths, the transmission loss is very high (low interference). $L$ decreases drastically at frequency window $12-18 \mathrm{GHz}$ and $30-40 \mathrm{GHz}$ and increases monotonously at frequency window $22-30 \mathrm{zGHz}$. This shows that the path attenuation is low; since the common volume is in the ice region, the decrease in reflectivity value will further enhance high transmission loss in the terrestrial system.

Figure 7 presents the variation of $L$ with percentage time unavailability at frequencies of $\mathrm{Ku}$ and $\mathrm{Ka}$ band frequency (12 and $30 \mathrm{GHz}$, resp.). The propagation path lengths from the terrestrial antenna to the common volume are 50 and $200 \mathrm{~km}$. The results show that $L$ increases as percentage time probability increases. At short path length of $50.7 \mathrm{~km}$ (TS-Cv distance of $50 \mathrm{~km}$ ), the transmission loss at the higher frequency of $30 \mathrm{GHz}$ is significantly higher than other frequencies due to larger path attenuation of the signal. Also at longer path 


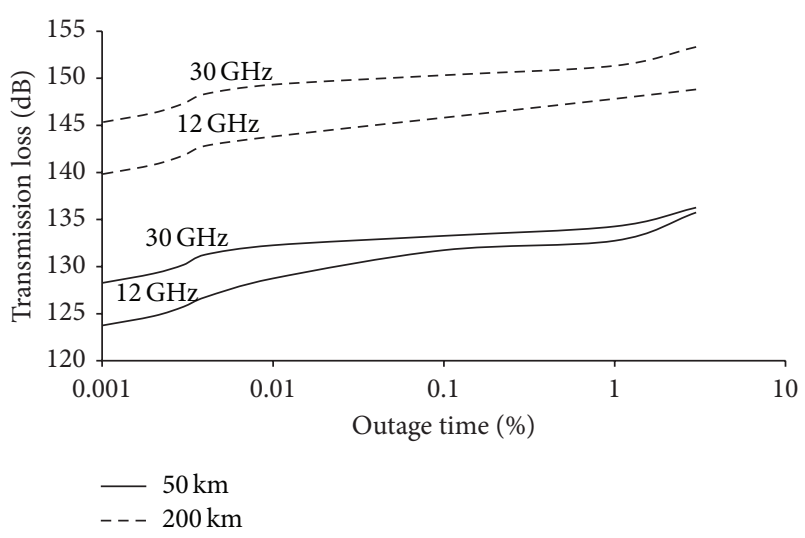

FIGURE 7: Variation of $L$ with percentage time unavailability at frequencies 12 and $30 \mathrm{GHz}$ over long and short path lengths.

length of $204.9 \mathrm{~km}$ (TS-Cv distance of $200 \mathrm{~km}$ ) $L$ is consistently higher than at short path length due to contribution of the ice region.

Figure 8 also shows the variation of the computed transmission loss with terrestrial antenna gain varying from 38 to $50 \mathrm{~dB}$ at frequencies of 12 and $25 \mathrm{GHz}$, respectively, over station separation of 50 and $200 \mathrm{~km}$. Generally speaking, transmission loss decreases linearly with increasing antenna gain for a given outage margin. Also, for a given terrestrial antenna gain, the transmission loss increases with decrease in channel availability. This trend could also be noticed (though not shown here due to paucity of space) at other frequencies and path length.

If two stations operating at the same frequency are separated from one another by a specific distance, situations can arise when rain attenuation on the path from a space station reduces the signal sufficiently to allow interference from a neighbouring earth station into the receiving earth station. The joint effects of attenuation of both wanted and unwanted signals then have to be considered. In Figure 9, we compare the effective transmission loss, Le, with the transmission loss, $L$, statistics at frequencies 10,12 , and $16 \mathrm{GHz}$ for varying time percentage unavailability in the study location. The results are for a propagation path length of $50 \mathrm{~km}$ from the terrestrial antenna to the common volume. The terrestrial antenna gain is assumed to be $45 \mathrm{~dB}$. The results show that Le decreases with increasing percentage time unavailability, while $L$ statistics are fairly constant. For time unavailability of $0.01 \%$, a difference of about 27,33 , and $42 \mathrm{~dB}$ could be noticeable between Le and $L$ statistics at 10,12 , and $16 \mathrm{GHz}$ frequencies, respectively. This kind of higher $\mathrm{dB}$ could not be overlooked in link budgeting design.

\section{Conclusion}

In this paper, we have presented some results on the application of simplified Bistatic 3D rain scatter model on horizontally polarized SHF signal propagation in the subtropical environment. Results are presented for a geostationary Intelsat satellite downlink terminal receiving interference from a terrestrial microwave system operating at the same frequency.

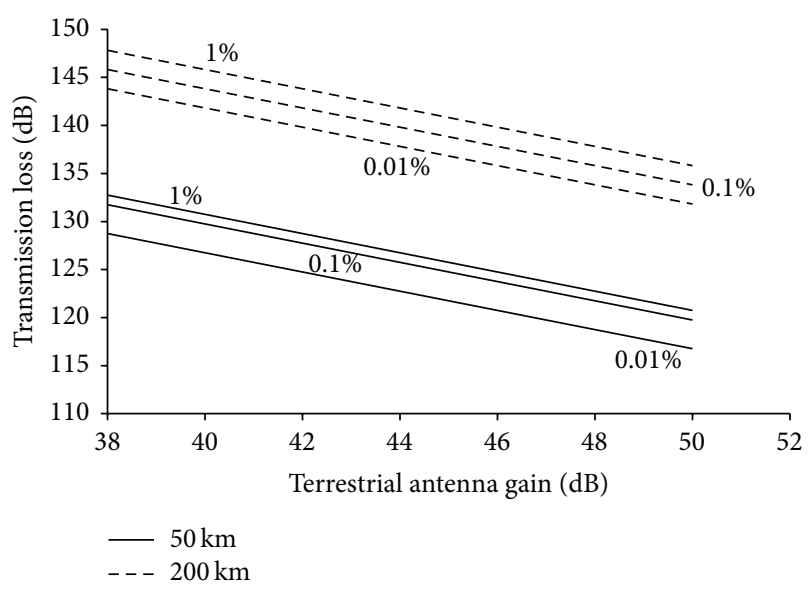

(a)

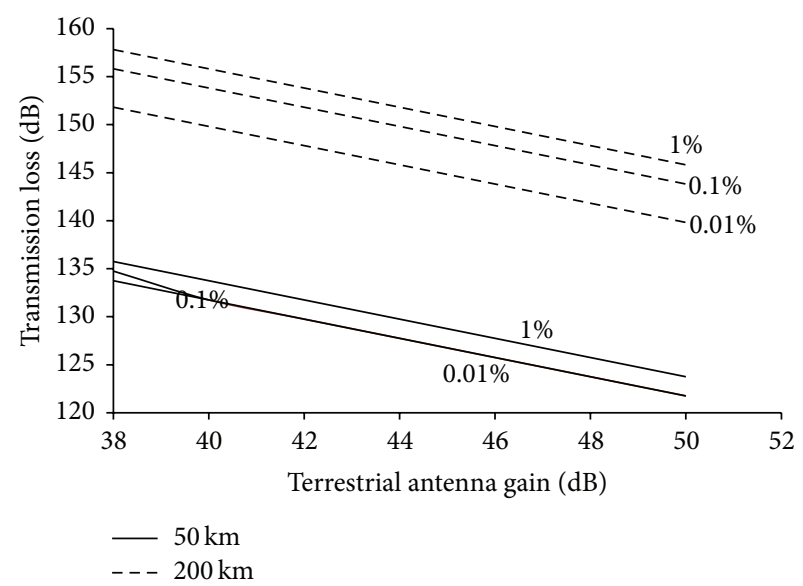

(b)

FIgURE 8: Influence of the computed transmission loss with terrestrial antenna gain over station separation of 50 and $200 \mathrm{~km}$ and at frequencies (a) 12 and (b) $25 \mathrm{GHz}$.

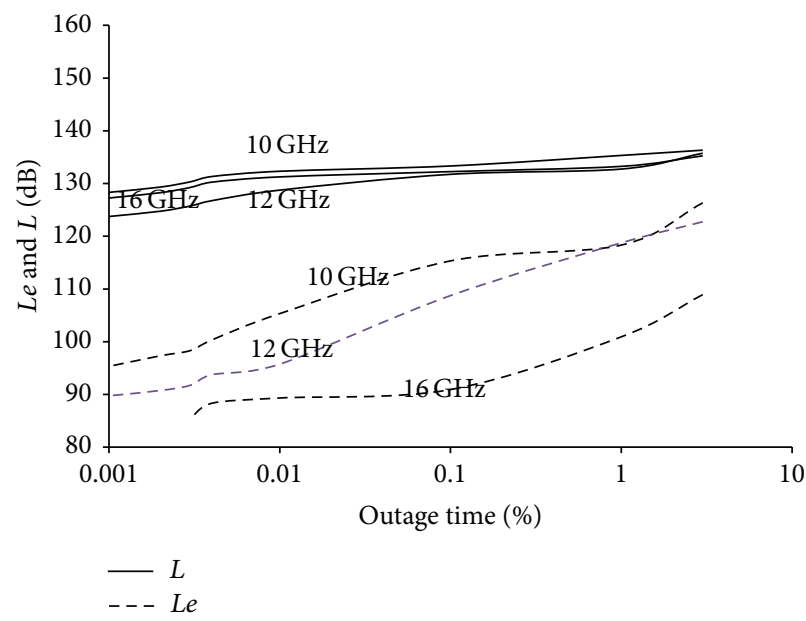

FIGURE 9: Comparison of the effective transmission loss and the transmission loss at different frequencies, path length of $50 \mathrm{~km}$ from terrestrial antenna to the common volume and at some percentage times. 
The result shows that when the station separation is longer than $150 \mathrm{~km}$, the transmission loss curve becomes steep in a strong received power region due to the decrease in radar reflectivity factor in the ice region. Though there is a less interference (significantly higher transmission loss) at a relatively higher frequency of 20 and $40 \mathrm{GHz}$, the rain scatter interference problem may not be negligible for a subtropical region with high rainfall rate because, for a small percentage of time, the rain scatter power can be received even at a large distance from an interfering station. Further results obtained based on the additional attenuation of the satellite signal show that, for time unavailability of $0.01 \%$, a difference of about 27,33 , and $42 \mathrm{~dB}$ could be noticeable between Le and $L$ statistics at 10 , 12 , and $16 \mathrm{GHz}$ frequencies, respectively. This kind of higher $\mathrm{dB}$ could not be overlooked in link budgeting design and if not properly taken care of can result to frequent problem of system outages in this location.

\section{Conflict of Interests}

The authors declare that there is no conflict of interests regarding the publication of this paper.

\section{References}

[1] L. Castanet, A. Bolea-Alamañac, and M. Bousquet, "Interference and fade mitigation techniques for $\mathrm{ka}$ and $\mathrm{Q} / \mathrm{V}$ band satellite communication systems," in Proceedings of the Internet Workshop of COST Actions 272 and 280 on Satellite Communications, from Fade Mitigation to Service Provision, vol. 272, ESTEC, Norwich, UK, 2003.

[2] C. Capsoni, F. Fedi, C. Magistroni, A. Paraboni, and A. Pawlina, "Data and theory for a new model of the horizontal structure of rain cells for propagation applications," Radio Science, vol. 22, no. 3, pp. 395-404, 1987.

[3] M. O. Ajewole and J. S. Ojo, "Intersystem interference due to hydrometeor scattering on satellite downlink signals in tropical locations," African Journal of Science and Technology (AJST) Science and Engineering Series, vol. 6, no. 2, pp. 84-93, 2005.

[4] R. K. Crane, "Bistatic scatter from rain," IEEE Transactions on Antennas and Propagation, vol. AP-22, no. 2, pp. 312-320, 1974.

[5] J. Awaka, "A 3D rain cell model for the study of interference due to hydrometeor scattering," Journal of the Communications Research Laboratory, vol. 36, no. 147, pp. 13-44, 1989.

[6] R. L. Olsen, D. V. Rogers, R. A. Hulays, and M. M. Z. Kharadly, "Interference due to hydrometeor scatter on satellite communication links," Proceedings of the IEEE, vol. 81, no. 6, pp. 914-922, 1993.

[7] A. R. Holt, R. McGuinness, D. G. Charlton, P. T. Thompson, and M. J. Mehler, "The development of a model to estimate the bistatic transmission loss associated with intersystem interference," IEEE Transactions on Antennas and Propagation, vol. 41, no. 10, pp. 1422-1431, 1993.

[8] C. Capsoni and M. D’Amico, "A physically based, simple prediction method for scattering interference," Radio Science, vol. 32, no. 2, pp. 397-409, 1997.

[9] S. P. Sitorus and I. A. Glover, "Rapid hydrometeor bistatic scatter calculations using non-orthogonal function expansion," International Journal of Satellite Communications, vol. 18, no. 3, pp. 207-218, 2000.
[10] M. O. Ajewole, L. B. Kolawole, and G. O. Ajayi, "Evaluation of bistatic intersystem interference due to scattering by hydrometeors on tropical paths," International Journal of Satellite Communications, vol. 17, no. 5, pp. 337-356, 1999.

[11] M. O. Ajewole, L. B. Kolawole, and G. O. Ajayi, "Theoretical study of the effect of different types of tropical rainfall on microwave and millimeter-wave propagation," Radio Science, vol. 34, no. 5, pp. 1103-1124, 1999.

[12] J. S. Ojo, S. K. Sarkar, and A. T. Adediji, "Intersystem interference on horizontally polarized radio signals in tropical climate," Indian Journal of Radio and Space Physics, vol. 37, no. 6, pp. 408413, 2008.

[13] J. S. Ojo and C. I. Joseph-Ojo, "An estimate of interference effect on horizontally polarized signal transmission in the tropical locations: a comparison of rain-cell models," Progress in Electromagnetics Research C, vol. 3, pp. 67-79, 2008.

[14] G. O. Ajayi and T. E. Owolabi, "Rainfall parameters from disdrometer dropsize measurements at a tropical station," Annales des Télécommunications, vol. 42, no. 1-2, pp. 3-12, 1987.

[15] International Telecommunication Union-Radio Communication Bureau, "Attenuation by atmospheric gases in the frequency range 1-350 GHz," Recommendation P.676-1, 2003.

[16] P. A. Owolawi and S. J. Malinga, "Computation of rain scattering properties at SHF and EHF for radio wave propagation in South Africa," in Proceedings of the URSI Commission F Triennial Open Symposium (URSI '13), Ottawa, Canada, 2013.

[17] P. A. Owolawi, "Raindrop size distribution model for the prediction of rain attenuation in Durban," Piers Online, vol. 7, no. 6, pp. 516-523, 2011.

[18] Commission of the European Communities on Cooperation in the Fields of Scientific and Technical Research, "COST project 210 campaign," Final Report EUR 13407EN-C, Commission of the European Communities on Cooperation in the Fields of Scientific and Technical Research, Brussels, Belgium, 1991.

[19] M. O. Fashuyi, P. A. Owolawi, and T. J. Afullo, "Rainfall rate modeling for Los radio systems in south Africa," SAIEE Africa Research Journal, vol. 97, no. 1, pp. 74-81, 2006.

[20] ITU-R, Water Vapour Surface Density and Total Columnar Content, Recommendation P.836, ITU, Geneva, Switzerland, 2013.

[21] R. S. Ray, "Broadband complex refractive indices of ice and water," Applied Optics, vol. 11, no. 8, pp. 1836-1844, 1972.

[22] http://www.satellite-calculations.com/Satellite/Downlink.htm.

[23] J. S. Ojo and R. C. Okeowo, "The application of 3D rain scatter model on horizontally polarized SHF signal propagation in tropical location," International Journal of Infrared and Millimeter Waves, vol. 29, no. 12, pp. 1136-1145, 2008. 

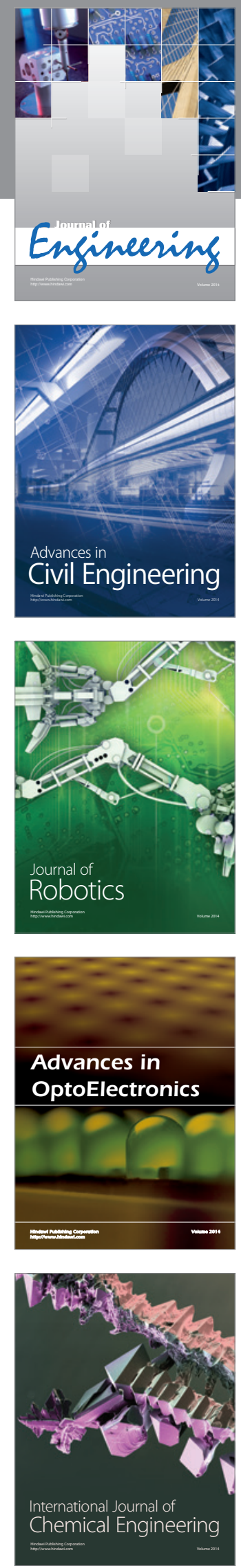

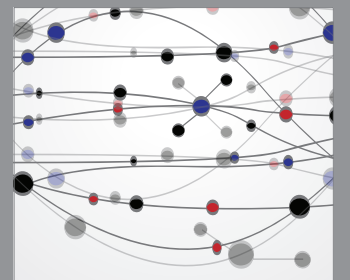

The Scientific World Journal
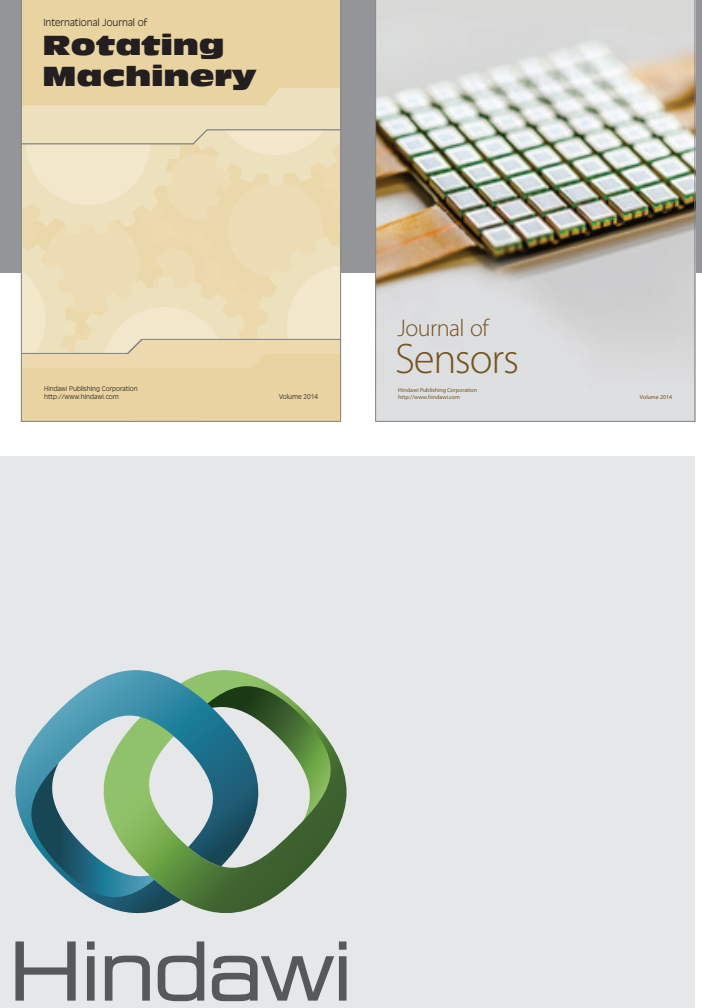

Submit your manuscripts at http://www.hindawi.com
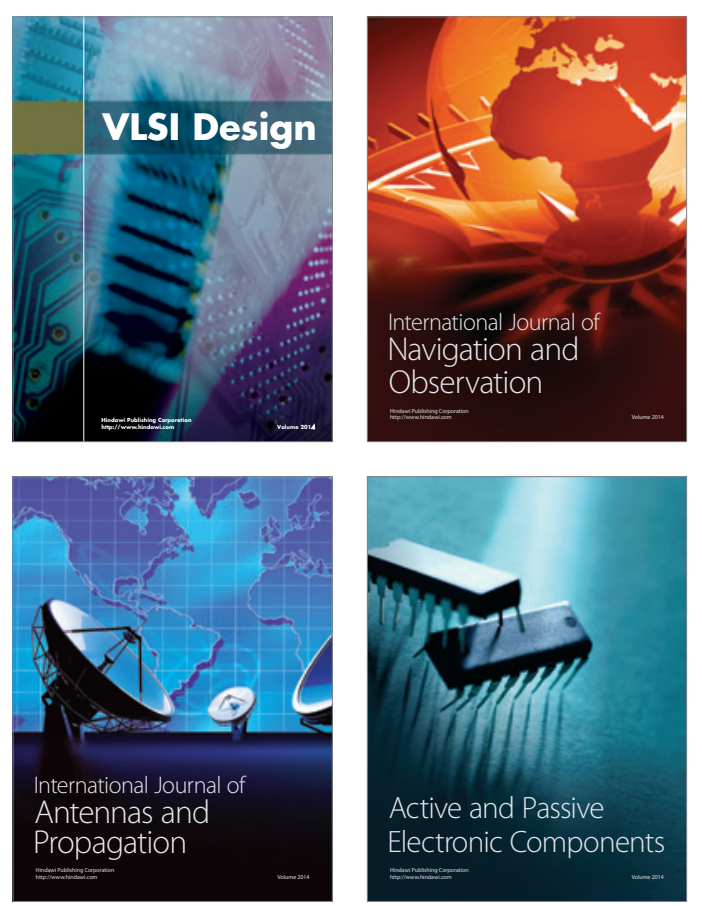
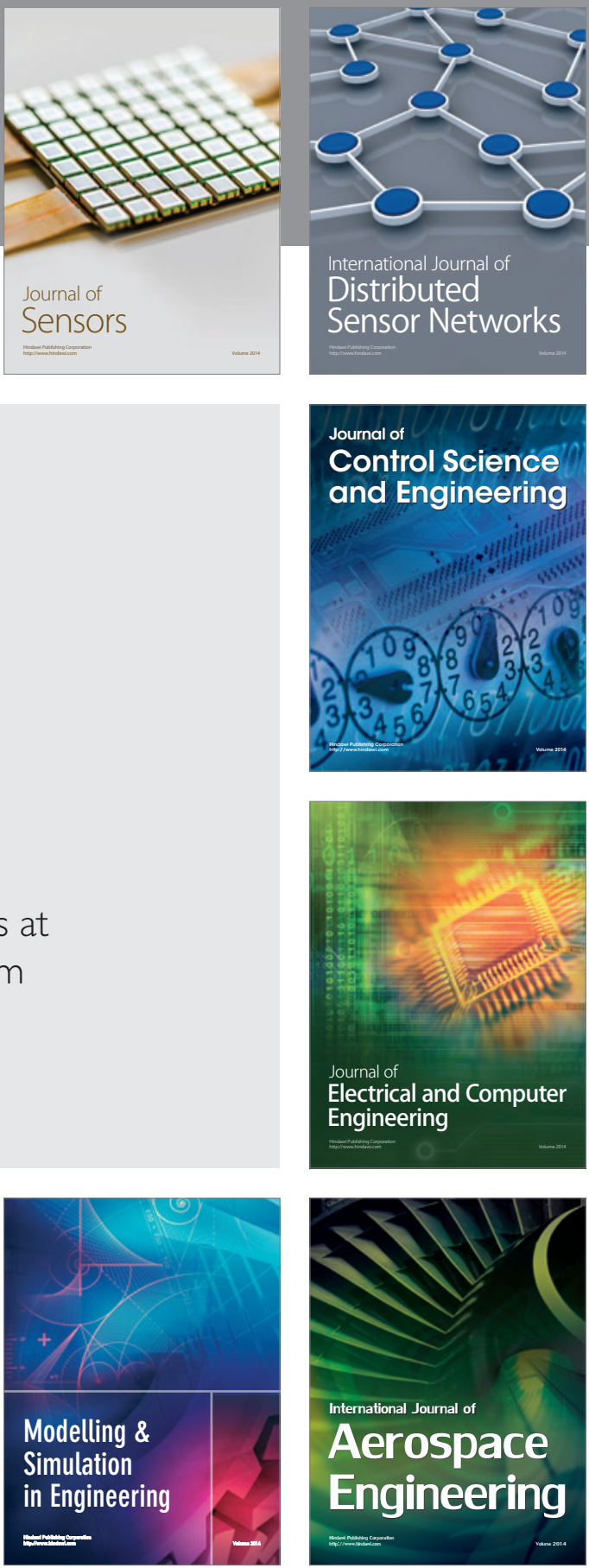

Journal of

Control Science

and Engineering
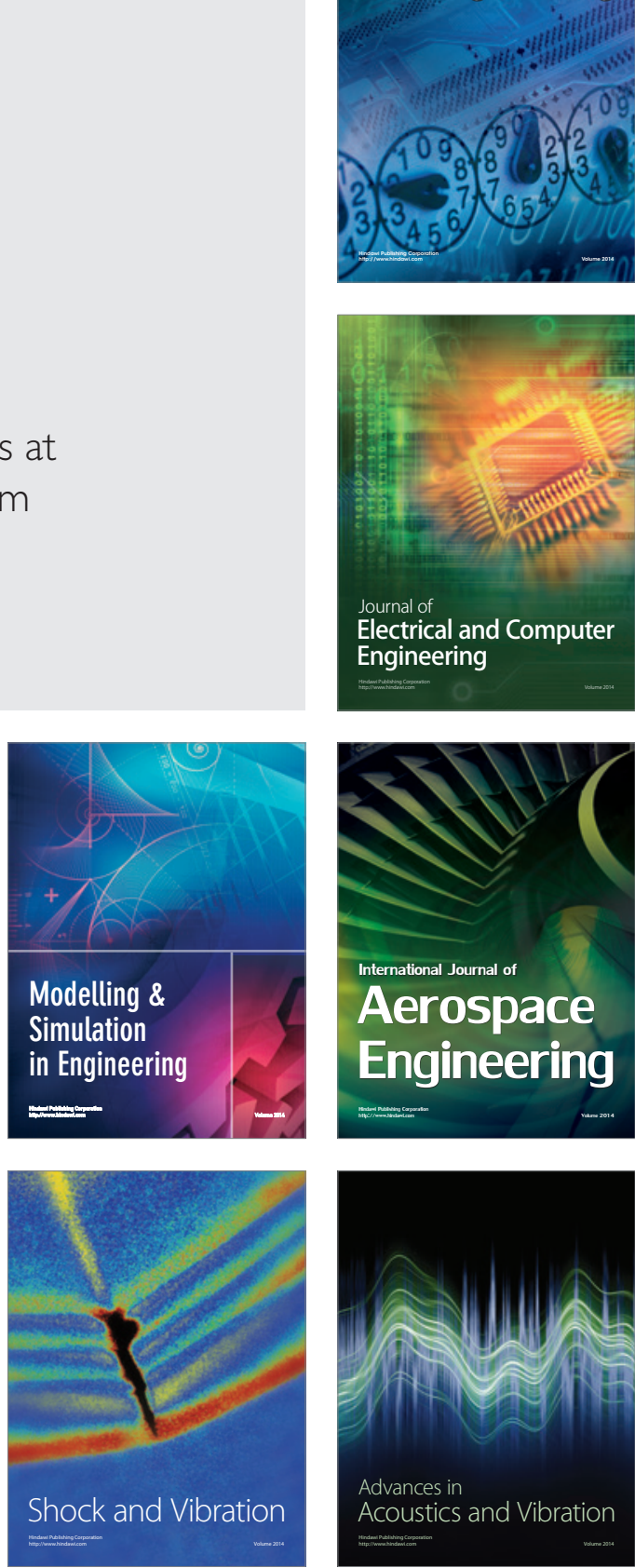